\title{
ACTIVITY AND SULFUR RESISTANCE OF Rh(I) AND Pd(II) COMPLEXES
}

Ivana Rivas, Juan Badano, Cecilia Lederhos, Domingo Liprandi, Edgardo Cagnola, Carlos Vera y Mónica Quiroga*

Departamento de Química, Facultad de Ingeniería Química, Universidad Nacional del Litoral / Instituto de Investigaciones en Catálisis y Petroquímica, Santiago del Estero 2654, S3000AOJ Santa Fe, Argentina

Recebido em 5/3/10; aceito em 4/8/10; publicado na web em 16/11/10

\begin{abstract}
Two complexes of $\mathrm{Rh}(\mathrm{I})$ and $\mathrm{Pd}(\mathrm{II})$ with chloride and tridecylamine ligands were obtained and characterized by Elementary Analysis and by XPS and FTIR spectroscopies. Complexes anchored on $\gamma-\mathrm{Al}_{2} \mathrm{O}_{3}$ were tested in the styrene semi-hydrogenation reaction carried out in the absence or presence of a sulfur poison. Although both low loaded catalysts were highly selective, the Pd(II) complex was three times more active than the Rh(I) complex. The rhodium complex was more sulfur resistant but less active than the palladium complex. Differences in conversion and sulfur resistance between both complexes could be related to electronic and/or geometric effects.
\end{abstract}

Keywords: Pd and Rh complexes; PYGAS selective hydrogenation; sulfur poisoning.

\section{INTRODUCTION}

Selective hydrogenation reactions have reached world scale importance because they allow to add value to cheap products of different processes and they permit the synthesis of complex compounds of importance for the petrochemical, pharmaceutical, food and fine chemistry industries. For example some highly reactive components of pyrolysis gasolines (PYGAS) can be transformed to suitable less reactive fuel components or aromatic compounds for petrochemistry. PYGAS streams contain aromatic compounds such as benzene, toluene and xylene (BTX), and also unsaturated compounds such as olefins and dienes. ${ }^{1}$ Due to their unstable character, diolefins and styrene should be eliminated to prevent the formation of gums in some refinery process units or during storage. The hydrogenation should be selective in order to keep the aromatic ring intact and preserve the commercial value of the stream. This reaction thus draws both industrial and academic, interest. ${ }^{1,2}$ Particularly the selective hydrogenation of styrene contained in BTX streams is important because is one of the components to be removed that reacts with the slowest rate. ${ }^{1,2}$

Different supports (alumina, carbon, etc.) and different metal precursors have been proposed for these catalysts. ${ }^{2,3}$ An important limitation concerning the life time of these catalysts is that they are severely poisoned by sulfur compounds usually present in many hydrocarbons sources. ${ }^{4}$ Another problem commonly present is the low selectivity of the catalysts in the case of some semi-hydrogenation reactions. For these reasons it is necessary to continuously develop more active, selective and sulfur resistant catalysts for the hydrogenation of hydrocarbons.

In the last decades some Group VIII transition metals complexes, supported or not, have begun to be used as catalysts for these kind of reactions. These complexes have proved to be more active, selective, and likewise more resistant to poisoning agents than the traditional metallic catalysts. ${ }^{5,6}$ Another advantage is that they can be used at milder reaction conditions. In previous publications of our group different types of metal complexes with different ligands were synthesized and they were found to be active, selective and sulfur resistant in the reaction of selective hydrogenation of double and triple bonds. ${ }^{6-8}$

The objectives of this work are: evaluate the catalytic activity of a palladium and a rhodium complex as low loaded heterogeneous catalysts without any pre-treatment for the selective hydrogenation

*e-mail: mquiroga@fiq.unl.edu.ar of styrene to ethylbenzene; study the resistance of these complexes to tetrahydrothiophene (THT) poisoning.

\section{EXPERIMENTAL}

\section{Catalysts preparation}

The Pd(II) and the $\mathrm{Rh}(\mathrm{I})$ complexes were obtained by the reaction of $\mathrm{PdCl}_{2}$ or $\mathrm{RhCl}_{3}$ with tridecylamine (TDA) in a balloon glass reactor at $353 \mathrm{~K}$ for $4.5 \mathrm{~h}$ with an argon inert atmosphere under reflux. Toluene was used as solvent and molar ratios of TDA/ $\mathrm{PdCl}_{2}=2$ or TDA/RhCl $=6$ were used. Complexes were purified by column chromatography, ${ }^{7}$ and the solvent was evaporated at vacuum pressure, thus obtaining the yellow Pd(II) and yellow-orange Rh(I) complexes.

The catalysts in their final form were obtained by loading 0.3 wt.\% of M (Pd or Rh) over cylindrical pellets of $\gamma-\mathrm{Al}_{2} \mathrm{O}_{3}$ Ketjen CK 300 using the incipient wetness impregnation technique. Pure chloroform was used as solvent for the impregnation of the Pd complex while a solution of Chloroform/Metanol (5\% v/v) was used in the case of the Rh complex.

\section{Characterization}

XPS spectra were obtained with a Shimadzu ESCA 750 electron spectrometer coupled to a data processor Shimadzu Escapac 760. The $\mathrm{BE}$ corresponding to $\mathrm{Pd}$ and $\mathrm{Rh} 3 \mathrm{~d}_{5 / 2}, \mathrm{~N} 1 \mathrm{~s}, \mathrm{Cl} 2 \mathrm{p}$ and $\mathrm{S} 2 \mathrm{p}$ and atomic ratios were determined for pure and anchored complexes following experimental procedures previously detailed elsewhere. ${ }^{6}$

FTIR spectra of TDA and the pure complexes were obtained in the range $4100-900 \mathrm{~cm}^{-1}$ using a Shimadzu $8101 / 8101 \mathrm{M}$ equipment. Further experimental details can be found elsewhere. ${ }^{7}$

$\mathrm{C}, \mathrm{H}$ and $\mathrm{N}$ content of the pure complexes were determined by elemental analysis in an Eager-2000 equipment. The complexes were analyzed by thermal gravimetry analysis (TGA) in a Setaran TG-DSC 92-16 equipment in order to determine their metal mass content. The use of the technique for the analysis of metal complexes has been reported elsewhere. ${ }^{9}$

\section{Catalytic evaluation}

The catalytic tests were carried out using $100 \mathrm{~mL}$ of a $5 \% \mathrm{v} / \mathrm{v}$ 
styrene/toluene solution (PF) and $0.1 \mathrm{~g}$ of the catalyst. $300 \mathrm{ppm}$ of THT (THT) were added to the PF solution for the poisoning tests. nDecane was used as an internal standard for chromatographic analysis.

The reaction was carried out in a stainless steel tank reactor covered with poly(tetrafluoroethylene) (PTFE), operated in semibatch conditions at $600 \mathrm{rpm}, 353 \mathrm{~K}$ and $500 \mathrm{kPa}$ of $\mathrm{H}_{2}$ pressure for $2 \mathrm{~h}$, using a styrene/metal molar ratios of $1.5 \times 10^{4}$. All catalytic tests were executed in triplicate, experimental error was ca. $3 \%$. The possibility of diffusional limitations was investigated following procedures previously reported. ${ }^{6}$ Neither external nor intraparticle diffusional limitations were observed. Samples were analyzed using a FID GC and a $30 \mathrm{~m} \mathrm{~J} \& W$ INNOWax $19091 \mathrm{~N}-213$ (cross-linked polyethylene glycol phase) capillary column.

The possible leaching of the complexes was followed by: atomic absorption analysis of the solution remaining after a reaction of 100 $\mathrm{h}$ length or after tests with a poison. Leaching was additionally assessed by comparison of the $\mathrm{M} / \mathrm{Al}$ atomic ratios obtained from XPS of the fresh and used catalysts (PF or THT).

\section{RESULTS AND DISCUSSION}

\section{Characterization}

Table 1 shows XPS BE and atomic ratios for the pure and heterogenized complexes. According to the literature, the measured $\mathrm{BE}$ values suggest the presence of $\mathrm{Cl}^{1-}, \mathrm{Pd}^{2+}$ and $\mathrm{Rh}^{1+} .{ }^{10} \mathrm{BE}$ values for $\mathrm{N}$ correspond to an ammonium-like nitrogen suggesting a bonding character of the nitrogen lone pair towards an electrophilic centre. ${ }^{10}$ XPS results indicate the following atomic ratios $\mathrm{Pd}: \mathrm{Cl}: \mathrm{N}=1: 2: 2$ and $\mathrm{Rh}: \mathrm{Cl}: \mathrm{N}=1: 1: 3$, so both complexes are tetracoordinated, and keep their chemical identities after heterogenization. Metal mass contents of $\mathrm{PdO}$ and $\mathrm{Rh}_{2} \mathrm{O}_{3}$ as obtained by TGA, previously reported, ${ }^{9}$ and data of the elementary analysis were used to corroborate these atomic ratios. The values of mass percentage of $\mathrm{C}, \mathrm{H}, \mathrm{N}$ and $\mathrm{M}$ previously reported for the pure Pd complex were 54.4, 10.1, 4.1 and 21.0\%, respectively. ${ }^{9}$ The corresponding values for the Rh complex were $62.3,11.3,4.0$ and $17.0 \% .{ }^{9}$ It seems important to remark the good agreement between the results of the three different techniques used.

It can be seen in Table 1 that the $\mathrm{Pd} / \mathrm{Al}$ atomic ratio is 1.8 times higher than the $\mathrm{Rh} / \mathrm{Al}$ atomic ratio. This suggests that the rhodium complex species migrate towards the interior of the alumina.

The BE and the atomic ratios did not vary before and after reaction. This suggests that the complex remained attached to the support without losing its chemical identity even after reaction.

The results of Table 1 indicate that after the reaction in the presence of THT the supported Pd complex has a smaller N/Pd atomic ratio and a new signal due to sulfur with a corresponding non-negligible $\mathrm{S} / \mathrm{Pd}$ atomic ratio. These results show the occurrence of a sulfur atom insertion in the metal atom's coordination sphere, replacing, at least partly, the nitrogen atoms of the tetracoordinated complex. On the other hand the $\mathrm{N} / \mathrm{Rh}$ atomic ratio of the supported $\mathrm{Rh}$ complex remains constant after this reaction. As a sulfur signal also appears in this case it can be supposed that the THT molecule is inserted in the coordination sphere of palladium without displacing the other ligands and thus forming a pentacoordinated complex. The THT molecule, as a competitive ligand, may tightly bind to the metal centre via the sulfur atom thus disturbing the catalytic cycle or even shutting it down. ${ }^{11}$ In this context the metal-sulfur bond strength may play a key role and as a result ethylbenzene production should decrease outstandingly in the presence of the poison. Additional work is however needed to evaluate whether there is also an effect of adsorption of the poison on the support, and if any, to what extent.

In Figure 1 the FTIR spectrum of pure tridecylamine shows the main peaks of an aliphatic primary amine: (A) $\mathrm{NH}_{2}$ "stretching" (3,600-3,100 cm-1$), C H$ "stretching" (3,000-2,800 $\left.\mathrm{cm}^{-1}\right)$, (B) $\mathrm{NH}_{2}$ "bending" (1,700-1,600 cm-1), CH "bending" (1,500-1,300 $\left.\mathrm{cm}^{-1}\right)$ and (C) CN "stretching" (1,200-1,000 $\left.\mathrm{cm}^{-1}\right)$, in total accordance with data of the literature. ${ }^{12} \mathrm{As}$ the nitrogen atom of the amine should be attached to the palladium or rhodium atom through the nitrogen lone pair, the ranges labelled $\mathrm{A}, \mathrm{B}$ and $\mathrm{C}$ indicate associated ranges for the nitrogen atom in the amine. These are used as a reference for comparative purposes. ${ }^{6}$

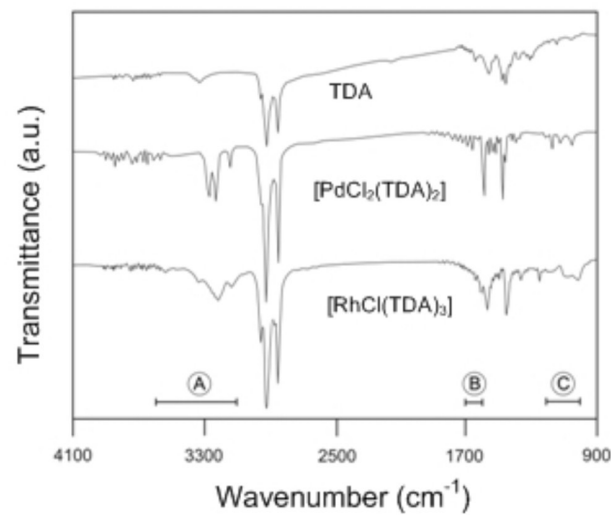

Figure 1. FTIR spectra of TDA, pure $\left[\mathrm{PdCl}_{2}(\mathrm{TDA})_{2}\right]$ and pure $\left[\mathrm{RhCl}(\mathrm{TDA})_{3}\right]$

As shown in Figure 1, the peaks of the FTIR spectra of the pure complexes are mainly in agreement with those corresponding to the pure TDA and these in turn with those reported in the literature. ${ }^{12}$ However some differences with regard to the pure tridecylamine, can be seen in the labelled A, B and C zones. There is a slight shift of the bands to lower wave number values due to the interaction with the metal atom through the lone pair of the nitrogen. ${ }^{6}$ This suggests the presence of TDA as a ligand in the coordination sphere.

On the basis of the results of TGA, elementary analysis, XPS and FTIR minimal formulae for the complexes can be proposed as $\left[\mathrm{PdCl}_{2}(\mathrm{TDA})_{2}\right]$ and $\left[\mathrm{RhCl}(\mathrm{TDA})_{3}\right]$.

Table 1. XPS binding energies and atomic ratios for pure, fresh and used heterogenized complexes, $\mathrm{M}=\mathrm{Pd}$ or Rh, PF: poison-free and THT: ${ }^{6}$ with poison

\begin{tabular}{|c|c|c|c|c|c|c|c|c|c|c|}
\hline Complex & Condition & $\begin{array}{c}\text { M } 3 \mathrm{~d}_{5 / 2} \\
(\mathrm{eV})\end{array}$ & $\begin{array}{l}\mathrm{N} \mathrm{s}_{1 / 2} \\
(\mathrm{eV})\end{array}$ & $\begin{array}{c}\mathrm{Cl} 2 \mathrm{p}_{3 / 2} \\
(\mathrm{eV})\end{array}$ & $\begin{array}{l}\text { S 2p } \\
(\mathrm{eV})\end{array}$ & $\begin{array}{l}\text { N/M } \\
\text { (at/at) }\end{array}$ & $\begin{array}{l}\mathrm{Cl} / \mathrm{M} \\
\text { (at/at) }\end{array}$ & $\begin{array}{c}\mathrm{S} / \mathrm{M} \\
\text { (at/at) }\end{array}$ & $\begin{array}{l}\text { M/Al } \\
\text { (at/at) }\end{array}$ & $\begin{array}{c}\text { S/Al } \\
\text { (at/at) }\end{array}$ \\
\hline$\left[\mathrm{PdCl}_{2}(\mathrm{TDA})_{2}\right]$ & pure & 338.2 & 402.0 & 198.2 & & 2.00 & 2.00 & & - & \\
\hline \multirow[t]{2}{*}[\mathrm{PdCl}_{2}(\mathrm{TDA})_{2}]{$/ \mathrm{Al}_{2} \mathrm{O}_{3}$} & $\mathrm{PF}$ & 338.3 & 401.7 & 198.2 & & 2.01 & 2.00 & & 0.09 & \\
\hline & THT & 338.4 & 401.7 & 198.2 & 162.8 & 1.00 & 2.01 & 1.09 & 0.09 & 79 \\
\hline$\left[\mathrm{RhCl}(\mathrm{TDA})_{3}\right]$ & pure & 307.1 & 402.1 & 198.1 & & 3.00 & 1.01 & & - & \\
\hline \multirow[t]{2}{*}[\mathrm{RhCl}(\mathrm{TDA})_{3}]{$/ \mathrm{Al}_{2} \mathrm{O}_{3}$} & $\mathrm{PF}$ & 307.2 & 402.2 & 198.3 & & 2.99 & 1.02 & & 0.05 & \\
\hline & THT & 307.3 & 402.1 & 198.2 & 162.9 & 2.99 & 1.00 & 0.99 & 0.05 & 20 \\
\hline
\end{tabular}




\section{Catalytic reaction test}

The only species detected by GC were styrene and ethylbenzene. The selectivity of the desired product was ca. $98 \%$. Pd or Rh were not detected by atomic absorption analysis of the remaining solution after $100 \mathrm{~h}$ of reaction in PF or THT solutions, indicating that the complexes remained anchored on the support.

Figure 2 shows styrene total conversion for both supported complexes during the hydrogenation reactions using the PF or THT solutions.

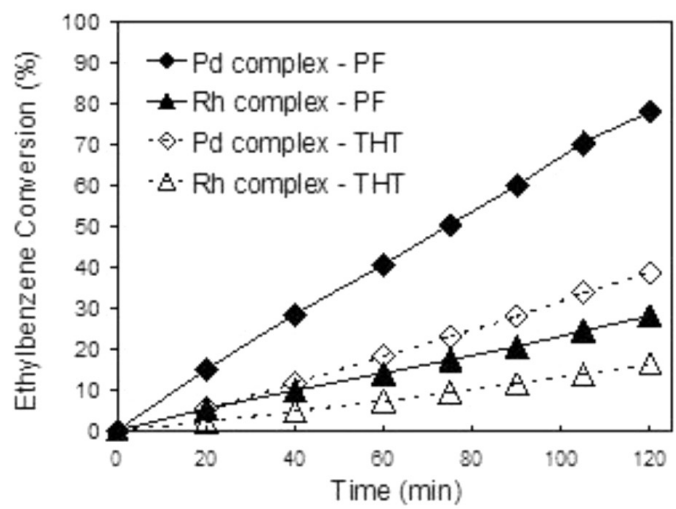

Figure 2. Styrene total conversion for $\left[\mathrm{PdCl}_{2}(\mathrm{TDA})_{2}\right] / \mathrm{Al}_{2} \mathrm{O}_{3}$ and $\left[\mathrm{RhCl}(\mathrm{TDA})_{3}\right] /$ $\mathrm{Al}_{2} \mathrm{O}_{3}$ in $\mathrm{PF}$ or $\mathrm{THT}$ conditions

It can be seen in Figure 2 that during the PF tests the values of conversion of styrene into ethylbenzene on the $\mathrm{Pd}$ and $\mathrm{Rh}$ complexes were 77.8 and $28 \%$, respectively after $2 \mathrm{~h}$ of reaction. These values indicate a marked difference in the activity of each catalyst. Figure 2 also shows that in the case of the THT tests the activity of both catalysts decreased notably: after 180 min a styrene conversion of 38 and 17\% wer obtained for the $\mathrm{Pd}(\mathrm{II})$ or $\mathrm{Rh}(\mathrm{I})$ anchored complex, respectively.

Assuming in all the cases a zero order of reaction ${ }^{13,14}$ the kinetic constant $(\mathrm{k})$ was calculated from the data of Figure 2. The relative decrease of activity after poisoning $\mathrm{R}_{\mathrm{THT}}$ detailed in Table 2, was determined from the activity data in the absence and presence of the poison $\left(\mathrm{k}_{\mathrm{PF}}\right.$ and $\mathrm{k}_{\mathrm{THT}}$, respectively) as: $\mathrm{R}_{\mathrm{THT}}=\left[\left(\mathrm{k}_{\mathrm{PF}}-\mathrm{k}_{\mathrm{THT}}\right) / \mathrm{k}_{\mathrm{PF}}\right] \mathrm{x} 100$. $\left[\mathrm{PdCl}_{2}(\mathrm{TDA})_{2}\right] / \mathrm{Al}_{2} \mathrm{O}_{3}$ is 2.8 times more active than $\left[\mathrm{RhCl}(\mathrm{TDA})_{3}\right] /$ $\mathrm{Al}_{2} \mathrm{O}_{3}$. A higher catalytic activity of $\mathrm{Pd} / \mathrm{Al}_{2} \mathrm{O}_{3}$ catalysts as compared to $\mathrm{Rh} / \mathrm{Al}_{2} \mathrm{O}_{3}$ catalysts has also been observed by Badano et al ${ }^{14}$ for metal contents of 0.05 and $0.35 \mathrm{wt} \%$. It can also be seen in Table 2 that the activity of the palladium catalyst decreased $50 \%$, while that of the rhodium catalyst decreased $40 \%$. These results indicate that $\left[\mathrm{RhCl}(\mathrm{TDA})_{3}\right] / \mathrm{Al}_{2} \mathrm{O}_{3}$ is more resistant to THT poisoning although is less active than $\left[\mathrm{PdCl}_{2}(\mathrm{TDA})_{2}\right] / \mathrm{Al}_{2} \mathrm{O}_{3}$.

Table 2. Activity $(\mathrm{k})$ and relative decrease of activity after poisoning $\left(\mathrm{R}_{\mathrm{THT}}\right)$

\begin{tabular}{cccc}
\hline Anchored complex & Solution & $\mathrm{k} \mathrm{x} 10^{5}\left(\mathrm{~s}^{-1}\right)$ & $\mathrm{R}_{\mathrm{THT}}(\%)$ \\
\hline$\left[\mathrm{PdCl}_{2}(\mathrm{TDA})_{2}\right]$ & $\mathrm{PF}$ & 10.76 & - \\
& $\mathrm{THT}$ & 5.38 & 50 \\
{$\left[\mathrm{RhCl}(\mathrm{TDA})_{3}\right]$} & $\mathrm{PF}$ & 3.84 & - \\
& $\mathrm{THT}$ & 2.31 & 40 \\
\hline
\end{tabular}

It is well known that metallic centres rich in electrons, as palladium and rhodium, could facilitate the rupture of the $\mathrm{H}_{2}$ molecule bond, due to the interaction of a filled metal $d$ orbital with the empty sigma antibonding $\mathrm{H}_{2}$ molecular orbital, taking place the weakening of the $\mathrm{H}-\mathrm{H}$ bond..$^{15,16}$ In both complexes, the effect of the decrease of the metal electronic availability produced by chloride ligands, is partially compensated by the contribution of electrons provided by the nitrogen atoms of the amine species. These characteristics are also relevant in the performance of the heterogeneous complexes, besides the important fact that an increase of styrene concentration exists in the environment of the complex anchored due to a base/acid of Lewis type interaction between the substrate (styrene) and the support $\left(\gamma-\mathrm{Al}_{2} \mathrm{O}_{3}\right)$, respectively. As the complex species of rhodium have three TDA ligands and a single chloride in its coordination sphere, while the complex species of palladium have two TDA and two chlorides ligands, it is possible to deduce that on the rhodium metallic center the electronic availability should be higher than that on the palladium center, making the Rh complex a more favorable specie as catalyst in semyhydrogenation reactions. On the other hand, taking into account the geometric factor, the size of the rhodium complex is bigger than that of the palladium one, and for that it would present a more important repulsive effect towards the entering substrate. It seems, from a nanoscopic point of view, that electronic and geometric effects play an opposite role to favour one of the complexes involved. However, for the present work, conversions values favour the palladium complex, this situation could be explained based on: the fact that the substrate, styrene, is a high electron density molecule thus presenting a more favorable interaction with the palladium complex because of its less size and electron availabitlity (geometric and electronic effect); and the experimental evidence that there exists a higher superficial concentration of the palladium complex on the support surface (M/Al XPS data on Table 1) meaning that there are more palladium species available as catalytic centers for the semi-hydrogenation process (structural effect).

Regarding the sulphur resistance, the poisoning results during the styrene hydrogenation in the presence of $300 \mathrm{ppm}$ THT showed in Table 2 , indicate that the $\left[\mathrm{RhCl}(\mathrm{TDA})_{3}\right]$ complex supported on $\gamma$-alumina is more sulphur resistant and that after the poisoning the coordination number increases from 4 to 5 due to the insertion of a sulphur atom in the coordination sphere of the supported complex. On the other hand, the results in Table 1 suggest that after the hydrogenation reaction in the presence of THT, there is a modification of the coordination sphere of palladium complex due to a sustitution of a TDA ligand by a THT molecule. Aditionally, it can be said that the $\mathrm{S}$ atom, in the THT molecule, could present a more important poisoning effect due to the presence of two lone electron pairs to be donated towards the central atom of each complex. On the other hand, $\mathrm{M}(\mathrm{Pd}$ or $\mathrm{Rh})$, according to XPS values, after being poisoned keeps almost the same oxidation state; this situation could be explained on the basis of some electron back donation effect from Pd or Rh towards the $\mathrm{S}$ element. This results in a less $d$ electron availability from $\mathrm{M}$ to produce $\mathrm{H}-\mathrm{H}$ bond rupture and consequently a decrease in its catalytic activity. However, the difference in the activity decrease, due to the presence of the poison, between both coordination compounds (50 vs. $40 \%$, for Pd and Rh complexes, respectively) could be explained using the XPS S/Al atomic ratios values showed in Table 1. These ratios indicate that some part of the surface support, blocked by the poison species, is no longer available for the substrate adsorption resulting in a less concentration of the species to be hydrogenated around the catalytic centers. The experimental values, $\mathrm{S} / \mathrm{Al}=79$ and 20 for $\mathrm{Pd}$ and $\mathrm{Rh}$ complexes, respectively, indicate that the local substrate concentration around the catalyst, is diminished around four times for the Pd complex respect to the Rh one. This structural fact could justify that the Rh complex is more sulfur resistant.

\section{CONCLUSIONS}

Supported complexes of palladium and rhodium with chloride and tridecylamine ligands were synthesized. The low loaded complexes anchored on $\gamma-\mathrm{Al}_{2} \mathrm{O}_{3}$ were used as heterogeneous catalysts in the 
styrene semi-hydrogenation under mild conditions. Although both catalysts were highly selective $\left[\mathrm{PdCl}_{2}(\mathrm{TDA})_{2}\right] / \mathrm{Al}_{2} \mathrm{O}_{3}$ was 2.8 times more active than $\left[\mathrm{RhCl}(\mathrm{TDA})_{3}\right] / \mathrm{Al}_{2} \mathrm{O}_{3}$.

The poisoning resistance studies using feedstocks with a concentration of $300 \mathrm{ppm}$ of tetrahydrothiophene indicate that the rhodium complex is more resistant to poisoning than the palladium complex. However $\left[\mathrm{PdCl}_{2}(\mathrm{TDA})_{2}\right] / \mathrm{Al}_{2} \mathrm{O}_{3}$ is still the most active catalyst. The coordination sphere of the complexes was affected differently by the poison. The Pd complex remained tetracoordinated but the poisoned $\mathrm{Rh}$ centres became pentacoordinated. The drop in activity and the sulfur resistance of both catalysts can be explained by resorting to geometric and/or electronic effects.

\section{ACKNOWLEDGMENTS}

The authors thank the financial support of UNL, CONICET and ANPCyT.

\section{REFERENCES}

1. Zhou, Z.; Cheng, Z.; Yang, D.; Zhou, X.; Yuan, W.; J. Chem. Eng. Data 2006, 51, 972 .

2. Gaspar, A. B.; Rosa dos Santos, G.; de Souza Costa, R.; Pereira da Silva, M. A.; Catal. Today 2008, 133, 400.

3. Lennon, D.; Marshall, R.; Webb, G.; Jackson, S. D.; Stud. Surf. Sci. Catal. 2000, 130, 245.

4. Boricha, A. B.; Mody, H. M.; Bajaj, H. C.; Jasra, R. V.; App. Clay. Sci. 2006, 31, 120.
5. Chen, B.; Dingerdissen, U.; Krauter, J. G. E.; Lansink Rotgerink, H. G. J.; Möbus, K.; Ostgard, D. J.; Panster, P.; Riermeir, T. H.; Seebald, S.; Tacke, T.; Trauthwein, H.; Appl. Catal., A 2005, 280, 17.

6. Cagnola, E.; Liprandi, D.; Quiroga, M.; L'Argentière, P.; App. Catal., A 2004, 74, 205.

7. Quiroga, M.; Liprandi, D.; Cagnola, E.; L'Argentiere, P.; Appl. Catal., A 2007, 326, 121.

8. Liprandi, D. A.; Cagnola, E. A.; Quiroga, M. E.; L'Argentière, P. C.; Catal. Lett. 2009, 128, 423.

9. Diaz-Auñón, J. A.; Román-Martínez, M. C.; L’Argentière, P. C.; SalinasMartínez de Lecea, C.; Studies Surf. Sci. Catal. 2000, 130, 2075.

10. NIST X-ray Photoelectron Spectroscopy Database NIST Standard Reference Database 20, Version 3.5 (Web Version), National Institute of Standards and Technology, USA, 2007.

11. Gates, B. C.; Catalytic Chemistry, Wiley: New York, 1992, chap. 1.

12. Silverstein, R. M.; Clayton Basler, G.; Morril, T. C.; Spectrometric Identification of Organic Compounds, $5^{\text {th }}$ ed., Wiley: New York, 1991, chap. III, p. 123.

13. Nijhuis, T. A.; Dautzenberg, F. M.; Moulijn, J. A.; Chem. Eng. Sci. 2003, $58,1113$.

14. Badano, J.; Lederhos, C.; Quiroga, M.; L'Argentière, P.; Quim. Nova 2010, 33, 48.

15. Nakamura, A.; Tsustsui, M.; Principles and Applications of Homogeneous Catalysis, John Wiley \& Sons: New York, 1980, p. 126.

16. Shriver, D. F.; Atkins, P. W.; Langford, C. H.; Inorganic Chemistry, $2^{\text {nd }}$ ed., Oxford University Press: Oxford, 1994, p. 258. 